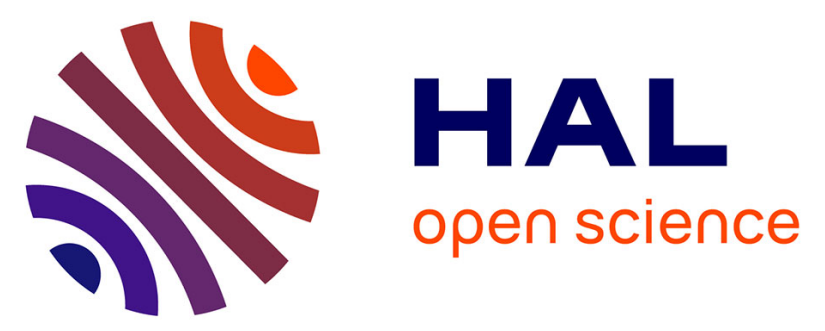

\title{
Relation between hysterectomy, oophorectomy and the risk of incident differentiated thyroid cancer: The E3N cohort
}

\author{
Agathe Guenego, Sylvie Mesrine, Laureen Dartois, Laurence Leenhardt, \\ Françoise Clavel-Chapelon, Marina Kvaskoff, Marie-Christine C \\ Boutron-Ruault, Fabrice Bonnet
}

\section{To cite this version:}

Agathe Guenego, Sylvie Mesrine, Laureen Dartois, Laurence Leenhardt, Françoise Clavel-Chapelon, et al.. Relation between hysterectomy, oophorectomy and the risk of incident differentiated thyroid cancer: The E3N cohort. Clinical Endocrinology, 2018, 10.1111/cen.13899 . hal-01952338

\section{HAL Id: hal-01952338 \\ https://hal-univ-rennes1.archives-ouvertes.fr/hal-01952338}

Submitted on 12 Dec 2018

HAL is a multi-disciplinary open access archive for the deposit and dissemination of scientific research documents, whether they are published or not. The documents may come from teaching and research institutions in France or abroad, or from public or private research centers.
L'archive ouverte pluridisciplinaire HAL, est destinée au dépôt et à la diffusion de documents scientifiques de niveau recherche, publiés ou non, émanant des établissements d'enseignement et de recherche français ou étrangers, des laboratoires publics ou privés. 
PROFESSOR FABRICE BONNET (Orcid ID : 0000-0001-9255-8228)

Article type : Original Article - Europe, excluding UK

\section{Relation between hysterectomy, oophorectomy and the risk of incident differentiated} thyroid cancer: the $\mathrm{E} 3 \mathrm{~N}$ cohort

A. Guenego $0^{1,2}$, S. Mesrine $e^{3,4}$, L. Dartois ${ }^{3,4}$, L Leenhardt ${ }^{5}$, F. Clavel-Chapelon ${ }^{3,4}$, M. Kvaskoff ${ }^{3,4}$, M.C. Boutron-Ruault ${ }^{3,4}$, F. Bonnet ${ }^{1,2,3}$

${ }^{1}$ CHU de Rennes, service d'Endocrinologie, F-35033 Rennes, France

${ }^{2}$ Univ Rennes1, F-35043 Rennes, France

${ }^{3}$ Université Paris-Saclay, Univ. Paris-Sud, UVSQ, Inserm U1018, CESP, Health across Generations team, F-94805, Villejuif, France

${ }^{4}$ Gustave Roussy, F-94805, Villejuif, France

${ }^{5}$ Thyroid and Endocrine Tumors Unit, Institut of Endocrinology, Pitié Salpêtrière Hospital, 75013

Paris, France

Running title : Hysterectomy, oophorectomy and the risk of thyroid cancer

Corresponding author: Marie-Christine Boutron-Ruault, Inserm U1018, CESP, Health across Generations team, EMT, Gustave Roussy, 114 rue Edouard Vaillant, 94805 Villejuif cedex, France

E.mail marie-christine.boutron@gustaveroussy.fr 
Keywords: thyroid cancer, hysterectomy, fibroids, oophorectomy

Disclosure Summary: The authors declare no potential conflicts of interest

Funding/support: This work was supported by the Mutuelle Générale de l'Education Nationale (MGEN); the European Community; the French League against Cancer (LNCC); Gustave Roussy; and the French National Institutes for Health and Medical Research (Inserm) The present study received grant support from the French National Cancer Institute (InCA) (\#2009-139).

Role of the sponsors: Funding sources had no involvement in the design and carrying out of the study, collection, management, analysis and interpretation of data, or preparation, review and approval of the manuscript.

\section{Acknowledgments}

The authors are grateful to all members of the E3N-EPIC study group, particularly to Marie Fangon, Pascale Gerbouin-Rérolle, Lyan Hoang, Rafika Chait, Céline Kernaleguen, Maryvonne Niravong, Maxime Valdenaire, and Gwenaëlle Guillas for their technical assistance. They are also indebted to all participants for providing data and to practitioners for providing pathology reports.

\section{Abstract}

Background: Thyroid cancers are threefold more frequent in women than in men. A role of reproductive or hormonal factors has been suggested but with contradictory results. We investigated potential associations between history of hysterectomy, with or without oophorectomy, and history of benign gynecological disease (uterine fibroids, endometriosis) and the incidence of differentiated thyroid cancer, in a large French prospective cohort. 
Methods: 89,340 women from the E3N cohort were followed up between 1990 and 2012 . Gynecological diseases treated by surgery were self-reported. Thyroid cancers were validated by histological reports. Time-dependent covariates included smoking status, BMI and history of benign thyroid disease. Cox proportional hazard models with age as time-scale were used to estimate Hazard Ratios (HR) and 95\% confidence intervals (Cl).

Results: 412 cases of thyroid cancer were diagnosed during follow-up. A history of hysterectomy was associated with an increased risk of differentiated thyroid cancer (adjusted $\mathrm{HR}=2.05 ; 95 \% \mathrm{Cl}: 1.65$ - 2.55). The association was not altered after further adjustment for reproductive factors. Endometriosis, uterine polyps, ovarian cysts and oophorectomy without hysterectomy were not associated with the risk of thyroid cancer. A history of fibroids was also significantly related to the risk of thyroid cancer over the follow-up period (adjusted $\mathrm{HR}=1.91 ; 95 \% \mathrm{Cl}$ : 1.50 - 2.44) and the increased risk persisted after adjustment for history of hysterectomy.

Conclusions: Women who had either a history of fibroids or hysterectomy had an increased risk of differentiated thyroid cancer. These findings suggest shared biological mechanisms between fibroids and thyroid cancer, which deserve to be further dissected.

\section{Introduction}

Incidence of thyroid cancer has increased worldwide over the recent decades $(1,2)$. Some established risk factors for thyroid cancer are known, such as ionizing radiation, benign thyroid disease, genetic predisposal and high body mass index (BMI) $(1,3,4)$. Based on epidemiological data, it has long been proposed that hormonal factors may determine or modulate the risk of thyroid cancer. Indeed, thyroid cancers are threefold more frequent in women than in men after puberty and incidence decreases after menopause $(5,6)$. A role of female hormones in the etiology of thyroid cancer has been suggested with a direct action of estrogens, via its receptors (ER), on proliferative and neoplastic disorders (6). However, the relationship between thyroid cancer risk and reproductive or hormonal factors is still debated, with contradictory and often inconclusive findings on the association between thyroid cancer and age at puberty, menopause, parity, breast-feeding or menopausal hormone therapy (5,7-9). 
Hysterectomy is one of the most common surgical procedures in gynecology worldwide and is mainly performed in case of a benign disease such as fibroma and endometriosis, conditions which are associated with lifetime sex steroid hormone exposure (10-12).

Several studies have attempted to determine hormonal and reproductive factors involved in the development of thyroid cancer in women, with conflicting results $(5,9,13)$. A potential association between hysterectomy and thyroid cancer risk has already been described, but in studies with methodological heterogeneities and potential bias $(7,14-17)$. Moreover, links between thyroid cancer risk and hysterectomy, oophorectomy, or benign gynecological disease histories have not been investigated simultaneously, despite common etiological factors and frequent morbid associations. Thus, we aimed to prospectively explore the link between differentiated thyroid cancer (micro or macro-carcinomas) and a history of hysterectomy, with or without oophorectomy, in a large cohort, according to age and time since gynecological surgery. In addition, we investigated the relation between a history of benign gynecological disease (uterine fibroids, endometriosis, ovarian cyst and uterine polyp and the risk of incident thyroid cancer.

\section{Materials and Methods}

The E3N cohort

The E3N cohort study (Etude Epidemiologique de Femmes de la Mutuelle Générale de l'Education Nationale) is a prospective cohort of 98,995 French women born between 1925 and 1950 and insured by a national health system primarily covering teachers (18). Participants have received 11 follow-up questionnaires (mailed every 2-3 years) and responded to each at a rate of $\sim 80 \%$ (18). The women were enrolled in 1990 after they returned a baseline self-administered questionnaire on their lifestyle and medical history. All women signed an informed consent, in compliance with the rules of the French National Commission for Data Protection and Individual Freedom from which approval was obtained.

\section{Thyroid disease assessment}

Each questionnaire inquired about cancer occurrence, and requested information and permission to contact participants' physicians. Cases were confirmed by pathology reports (18). Here, we 
considered only histologically confirmed first incident primary differentiated thyroid cancer cases (i.e. papillary (International Classification of Diseases for Oncology, ICD-O codes: 8050, 8052, 8130, 8260, 8263, 8340-8344, 8350, 8450) and follicular (8290, 8330-8335, 8480, 8490)), excluding 21 cases of anaplastic or medullary thyroid cancer. Micro- and macro-carcinomas were defined as tumors sized $<10 \mathrm{~mm}$ and $\geq 10 \mathrm{~mm}$, respectively.

Each questionnaire also inquired about diagnoses of dysthyroidism (hyperthyroidism or hypothyroidism), and of benign morphological thyroid conditions.

Assessment of hysterectomy and benign gynecological diseases

Hysterectomy and oophorectomy status (none, or uni- or bilateral), and age at surgery were recorded in each questionnaire. Benign gynecological diseases considered in this analysis were endometriosis, ovarian cysts, fibroids, and uterine polyps recorded in each questionnaire. Ovarian cysts reported by women diagnosed with endometriosis were not considered, to avoid potentially misdiagnosed ovarian endometrioid cyst cases. For all diseases, diagnostic procedures as laparoscopy, biopsy, hysterography, hysteroscopy, or ultrasonography were recorded in the 1992, 1993, and 1994 questionnaires and surgical treatments were available in each questionnaire except the baseline questionnaire. For each gynecological disease, we separately considered those confirmed by surgery or laparoscopy, confirmed by at least one treatment or diagnosis exam, and only self-reported gynecological diseases.

Population for analysis

Follow-up started at the date of return of the 1990 questionnaire. Participants contributed personyears of follow-up until the date of diagnosis of any cancer (except basal-cell carcinoma and in situ colorectal cancer), the date of the last completed questionnaire, or December 2011 (date of mailing of the 10th questionnaire), whichever occurred first. Women studied were censored at the date of a first thyroid cancer and we did not consider a hysterectomy or other benign gynecological diseases which occurred following a first thyroid cancer. Among the 98,995 women included in the study, we excluded those who reported a prevalent cancer at baseline other than a basal cell cancer or in situ colorectal cancer $(n=4,844)$, and women with no follow-up data $(n=2,073)$, with primary amenorrhea or unknown age at menarche $(n=2209)$, with missing information on age at hysterectomy or oophorectomy $(n=$ 418 ), or with unknown date of cancer diagnosis $(n=111)$, ending up with 89,340 women for analysis. 
Statistical analyses

Cox proportional hazard models with age as time-scale were used to estimate Hazard Ratios (HR) and $95 \%$ confidence intervals $(\mathrm{Cl})$ of first differentiated thyroid cancer associated with history of hysterectomy or benign gynecological disease. Women diagnosed with non-differentiated thyroid cancer were censored at the date of diagnosis. Hysterectomy status or benign gynecological disease variables were analyzed as time-dependent variables. When the variables were not available at a given questionnaire, the preceding value was considered until the next known value. The proportional hazard hypothesis was verified for all time-independent variables of interest using log-log survivor plots. Covariates included in the models used are listed in Tables 2 and 3. Information on timedependent variables was updated at each questionnaire Missing values for all adjustment variables were replaced by the modal value, as they were missing for less than $5 \%$ of women.

We performed stratified analyses to explore associations according to tumor size (micro- $(<10 \mathrm{~mm})$ or macro- ( $\geq 10 \mathrm{~mm}$ ) carcinoma) using competing-risk models. Cases with missing values on tumor size were excluded from these analyses and analyses were performed in each strata by censoring the cases belonged to the other strata at date of diagnosis.

We used homogeneity tests to compare risk estimates across strata using the Wald chi-square statistic.

Smoking status and a history of dysthyroidism were evaluated as potential effect modifiers by adding an interaction term in the final model and testing statistical significance. All tests were two-sided and statistical significance ( $p$-value) was set at the 0.05 level. All analyses were performed using Statistical Analysis Systems (SAS) software, version 9.3 (SAS Institute, Inc, Cary, North Carolina).

\section{Results}

Among 89,340 women considered in the present analysis, 412 cases of first primary differentiated thyroid cancer (381 papillary and 31 follicular) were diagnosed during 1,603,264 person-years of observation (median follow-up duration of 9.9 years for cases and 21.4 years for non-cases). Of the 412 cases of thyroid cancer, the information on the micro or macro carcinoma status was missing for 9. A total of $166(41 \%)$ were considered as micro carcinoma (size $<10 \mathrm{~mm}$ ) and 237 were macrocarcinoma (size $\geq 10 \mathrm{~mm}$ ). 
As shown in Table 1, the frequency of goiter/thyroid nodules was similar between women with an history of hysterectomy and those who did not have hysterectomy. The prevalence of excessive weight or obesity was higher among the women with an history of hysterectomy as compared to those without hysterectomy.

Hysterectomy/ Oophorectomy and risk of thyroid cancer

Women with a history of hysterectomy had an increased risk of differentiated thyroid cancer $(\mathrm{HR}=2.05,95 \% \mathrm{Cl} 1.65-2.55$; model 2), as compared to women without hysterectomy (Figure 1, Table 2). When considering types of hysterectomy/oophorectomy, the highest risk was observed for women with hysterectomy and uni- or bilateral oophorectomy $(\mathrm{HR}=2.21,95 \% \mathrm{Cl} 1.67-2.91)$. There was no association between oophorectomy alone and thyroid cancer risk. Risks were similar whatever the age at the hysterectomy or the time since hysterectomy. Associations were similar although slightly stronger after adjustment for reproductive factors (model 3) (Table 2). Results were similar for papillary and follicular cancers $(\mathrm{HR}=2.02,95 \% \mathrm{Cl} 1.61-2.53$ for papillary, $\mathrm{HR}=2.52,95 \% \mathrm{Cl}$ 1.17-5.44 for follicular, $P_{\text {homogeneity }}=0.59$, model 2$)$. Both micro- and macro-carcinomas $((\mathrm{HR}=1.81$, $95 \% \mathrm{Cl} 1.28-2.57$ and $\mathrm{HR}=2.16,95 \% \mathrm{Cl} 1.62-2.88$ respectively, $P_{\text {homogeneity }}=0.45$, model 2 ) were associated with a history of hysterectomy.

The association between a history of hysterectomy and thyroid cancer risk was not modified by smoking status nor dysthyroidism history $\left(P_{\text {interaction }}=0.09\right.$ and 0.23 , respectively $)$ and was observed in all corresponding strata.

Fibroids

Overall, a history of benign gynecological disease confirmed by surgery or laparoscopy was associated with increased thyroid cancer risk (HR 1.67, 95\% $1.32-2.11$; model 2) (Table 3). The increase was driven by the association with uterine fibroids history (HR 1.91; $95 \% \mathrm{Cl} 1.50-2.44$, model 2) (Table 3). This association was observed whatever the mode of diagnosis of fibroids and irrespective of a history of hysterectomy (Table 3). Women with a confirmed history of fibroids had an increased risk of both micro- $(\mathrm{HR}=1.54,95 \% \mathrm{Cl} 1.03-2.30$, model 2$)$ and macro-carcinomas $(\mathrm{HR}=2.16$, $95 \% \mathrm{Cl} 1.57-2.97$, model 2). If we consider simultaneously history of hysterectomy and of fibroids in the same multivariate statistical model (model 2), each variable remains statistically associated with 
the risk of thyroid cancer [hysterectomy (yes/no): $\mathrm{HR}=1.70,95 \% \mathrm{Cl}: 1.27-2.28$; history of fibroids (yes/no): HR=1.33, 95\% Cl :1.01 - 1.75].

Neither self-reported nor confirmed history of endometriosis, uterine polyps or ovarian cysts were associated with thyroid cancer risk (Table 3). Results were similar for papillary and follicular thyroid cancers (data not shown).

Finally, we performed sensitivity analyses by excluding women who had an early diagnosis of thyroid cancer (first 2 years of follow up) and the results were unchanged: women with a history of hysterectomy had an increased risk of differentiated thyroid cancer $(\mathrm{HR}=2.01,95 \% \mathrm{Cl} 1.60-2.52$; model 2), as compared to women without hysterectomy. Similarly, those who had a history of uterine fibroma were at higher risk of thyroid cancer as well (HR 1.84; $95 \% \mathrm{Cl} 1.47-2.30$, model 2).

\section{Discussion}

In this large prospective study with more than 400 incident thyroid cancer cases occurring in women aged 40-65 at baseline, we found a positive relationship between the risk of differentiated thyroid cancer and a history of hysterectomy, but not with a history of oophorectomy. Results were similar whatever the age at hysterectomy or time since hysterectomy. We observed also an association between a history of fibroids and the risk of thyroid cancer, which appears to be independent of a history of hysterectomy.

Hysterectomy/oophorectomy status and risk of thyroid cancer

A recent meta-analysis reported an association between a history of hysterectomy and the risk of thyroid cancer with a summary relative risk (SRR) of 1.43 (5). However, the results were contrasting as only five out of 24 studies found that hysterectomy was associated with an increased risk of thyroid cancer. Other studies focusing specifically on the link between differentiated thyroid cancer risk and a history of hysterectomy were also conflicting $(7,11,14,15,17,19,20)$. Methodological flaws may partly explain these discrepancies, due to case-control design and retrospective self-reported surgery history. Besides, studies concluding that there was a positive relationship between a history of hysterectomy and thyroid cancer risk did not perform adjustment on history of benign thyroid disease 
or family history of thyroid cancer, and thus could not discard the possibility of confounding $(14,15,17,19)$.

In contrast to previous studies $(14,15,17)$, we did not observe any change in the association between hysterectomy and the risk of thyroid cancer in relation to the time elapsed since hysterectomy or according to the age at hysterectomy. This finding is an argument against a potential detection bias associated to gynecological surgery. However, we cannot exclude such a detection bias. It could be speculated that thyroid cancer may be more likely to be found among women with hysterectomy or fibroids, because of medical attention received, as compared to those without the conditions. However, the slightly stronger relation observed between hysterectomy or fibroids and macro-cancers compared with micro-cancers is not in favor of a potential screening bias, which involved the detection of a majority of microcarcinoma.

Surgically-induced menopause, often defined in studies as hysterectomy and/or bilateral oophorectomy has previously been associated with an increased risk of thyroid cancer $(8,16,21)$. When we considered simultaneously hysterectomy and oophorectomy status, we found that a history of oophorectomy was not related to the risk of thyroid cancer and did not substantially affect the association between hysterectomy and thyroid cancer. This is consistent with the WHI cohort for which Kabat et al (7) did not find any association between thyroid cancer risk and bilateral oophorectomy. Some authors found either a higher $(22)$, a lower $(15,17)$ or a similar $(11,14,16)$ risk of thyroid cancer in women with hysterectomy and bilateral oophorectomy compared to women with hysterectomy alone or hysterectomy with partial oophorectomy.

Benign gynecological diseases history and risk of thyroid cancer

Our study revealed a positive association between a history of fibroids and the risk of differentiated thyroid cancer, which is consistent with the relationship between hysterectomy and thyroid cancer as uterine fibroids are the most common cause of hysterectomy (12). The twofold increased risk of thyroid cancer linked to surgically treated fibroids was similar to results reported in two American studies $(11,15)$.

Studies on the relationship between endometriosis history and thyroid cancer risk are more conflicting, with HR/SIR varying between 0.85 and 3.09. Only two studies found an increased risk of thyroid cancer in women with an endometriosis evolving from more than 5 years (23) and in parous 
women (24). It may reflect discrepancies in the definition of endometriosis cases, differences in the populations and the design of the studies: some used retrospective cohort of infertile women (25), other used data extracted from inpatient and cancer registers $(23,24,26)$ or self-reported endometriosis history (12).

As previous studies (11), we found no relationship between an ovarian cyst history and thyroid cancer risk, which is in line with the lack of link between oophorectomy and thyroid cancer in our study.

Our results seem not to be related to detection bias. Uterine fibroids are the most common pelvic tumors, occurring in nearly $70 \%$ of all reproductive-aged women (12). Hyper- or hypothyroidism both enhance the likelihood of their diagnosis or treatment (27) by causing abnormal uterine bleeding, and have been linked with an increased risk of differentiated thyroid cancer $(28,29)$. However, the fact that we found a similar thyroid cancer risk whatever the time elapsed since surgery argues against this. Moreover, the slightly stronger relation observed between hysterectomy or fibroids and macrocancers compared with micro-cancers is not in favor of a potential screening bias.

Potential mechanisms linking uterine fibroids and differentiated cancer thyroid

Uterine fibroids have been associated with thyroid nodules $(30,31)$ and hypothyroidism (32) in transversal studies, suggesting shared mechanisms between fibroids and thyroid diseases. Both fibroids and thyroid cancers are thought to be sex steroid dependent.

If the link between hormonal factors and the risk of fibroids is well established (11), the relationship between sex hormones and thyroid cancer is much less characterized. Both estrogen receptors $\alpha$ (ER $\alpha$ ) with a proliferative and anti-apoptotic function, and estrogen receptors $\beta(E R \beta)$ with a pro-apoptotic function, are expressed in normal and thyroid tumor cells. Thyroid cell proliferation and neoplastic development might depend on the imbalance between ER $\alpha$ and $\operatorname{ER} \beta(6,33)$. Moreover, progesterone receptors have already been described in thyroid follicular cells, and progesterone has been shown to upregulate genes involved in thyroid function and growth on normal human thyroid cells in vitro (34). Besides, thyroid cancer cells and fibroids are both able to biosynthesize estradiol in situ through the action of aromatase $(35,36)$. 
However, the link between hormonal factors and thyroid cancer remain inconclusive in several studies (5,7-9) suggesting that not only direct estrogen action but other pathways may be shared between fibroids and thyroid cancer, such as growth factors pathways and TSH/ thyroid hormones induced pathways. Growth factors and non-genomic estradiol pathways converge towards the aberrant activation of Ras/Raf/MEK/ERK and PI3K/Akt/mTOR signaling in both thyroid and fibroids cells. In addition, due to common nucleotide sequence in ER and thyroid hormone receptor, these receptors can interact and regulate several transcriptional responses to environmental stimuli (37). Moreover, thyrotropin-releasing hormone (TRH), thyroid-stimulating hormone (TSH), and thyroid hormone receptors were shown to be present in monkey uterus (38). Another study described a smooth muscle cells proliferation after stimulation by TSH (39).

Somatic genetic mutations play a part in the molecular pathogenesis of both fibroids (MED12 mutations) (12) and differentiated thyroid cancer (eg BRAF mutations) (1). Thus a chronic reduction in DNA repair capacity might explain partly a common susceptibility to differentiated thyroid cancer and fibroids. The increased risk of both thyroid cancer and fibroids in atomic bomb survivors illustrates this hypothesis (40). Increased insulin resistance or related hyperinsulinemia might be a common underlying factor shared by women with uterine fibroids which may predispose to the development of thyroid cancer as recently suggested (41).

Strengths and limits

Strengths of our study include its prospective design, large sample size, histological confirmation of all thyroid cancer cases, and availability of data for most differentiated risk factors including a history of benign thyroid conditions. Exposure data were collected before diagnosis of thyroid cancer, avoiding potential recall biases. To our knowledge, it is the first study that investigated an association between hysterectomy, uterine fibroids and micro- and macro- thyroid cancer risk.

This cohort is not representative of the French population and our results cannot be extrapolated to the entire French population. As in all observational studies, residual confounding may subsist. Misclassification of exposure status is a potential limitation because of the self-reported assessment of surgery, benign gynecological and thyroid diseases. Moreover, when we restricted the analysis to the treated cases, the associations remain consistent. Women included in our study, although 
younger than in the WHI and PLCO studies, were mostly postmenopausal, and our results may not be generalizable to young premenopausal women.

Conclusion

Our findings showed that hysterectomy or a history of fibroids were associated with a twofold increased risk of differentiated thyroid cancer (micro- and macro-carcinomas) in mostly postmenopausal women. This relation might be explained by common signaling pathways regulated by estrogen, progesterone, or TSH/thyroid hormones. Further studies are needed to delineate the underlying molecular mechanisms or pathways.

\section{References}

1. Schneider DF, Chen $\mathrm{H}$. New developments in the diagnosis and treatment of thyroid cancer. CA. Cancer J. Clin. 2013;63(6):374-394.

2. Colonna M, Uhry Z, Guizard AV, Delafosse P, Schvartz C, Belot A, Grosclaude P, FRANCIM network. Recent trends in incidence, geographical distribution, and survival of papillary thyroid cancer in France. Cancer Epidemiol. 2015;39(4):511-518.

3. Clavel-Chapelon F, Guillas G, Tondeur L, Kernaleguen C, Boutron-Ruault M-C. Risk of differentiated thyroid cancer in relation to adult weight, height and body shape over life: the French E3N cohort. Int. J. Cancer 2010;126(12):2984-2990.

4. Trésallet $C$, Seman $M$, Tissier F, Buffet $C$, Lupinacci RM, Vuarnesson $H$, Leenhardt $L$, Menegaux $F$. The incidence of papillary thyroid carcinoma and outcomes in operative patients according to their body mass indices. Surgery 2014;156(5):1145-1152.

5. Caini S, Gibelli B, Palli D, Saieva C, Ruscica M, Gandini S. Menstrual and reproductive history and use of exogenous sex hormones and risk of thyroid cancer among women: a meta-analysis of prospective studies. Cancer Causes Control 2015;26(4):511-518.

6. Derwahl M, Nicula D. Estrogen and its role in thyroid cancer. Endocr. Relat. Cancer 2014;21(5):T273-283.

7. Kabat GC, Kim MY, Wactawski-Wende J, Lane D, Wassertheil-Smoller S, Rohan TE. Menstrual and reproductive factors, exogenous hormone use, and risk of thyroid carcinoma in postmenopausal women. Cancer Causes Control 2012;23(12):2031-2040.

8. Zamora-Ros R, Rinaldi S, Biessy C, Tjønneland A, Halkjaer J, Fournier A, Boutron-Ruault M-C, Mesrine S, Tikk K, Fortner RT, Boeing H, Förster J, Trichopoulou A, Trichopoulos D, Papatesta E-M, Masala G, Tagliabue G, Panico S, Tumino R, Polidoro S, Peeters PHM, Bueno-deMesquita HB, Weiderpass E, Lund E, Argüelles M, Agudo A, Molina-Montes E, Navarro C, Barricarte A, Larrañaga N, Manjer J, Almquist M, Sandström M, Hennings J, Tsilidis KK, Schmidt JA, Khaw K-T, Wareham NJ, Romieu I, Byrnes G, Gunter MJ, Riboli E, Franceschi S. Reproductive and menstrual factors and risk of differentiated thyroid carcinoma: the EPIC study. Int. J. Cancer 2015;136(5):1218-1227. 
9. Wang P, Lv L, Qi F, Qiu F. Increased risk of papillary thyroid cancer related to hormonal factors in women. Tumour Biol. J. Int. Soc. Oncodevelopmental Biol. Med. 2015;36(7):5127-5132.

10. Hammer A, Rositch AF, Kahlert J, Gravitt PE, Blaakaer J, Søgaard M. Global epidemiology of hysterectomy: possible impact on gynecological cancer rates. Am. J. Obstet. Gynecol. 2015;213(1):23-29.

11. Braganza MZ, de González AB, Schonfeld SJ, Wentzensen N, Brenner AV, Kitahara CM. Benign breast and gynecologic conditions, reproductive and hormonal factors, and risk of thyroid cancer. Cancer Prev. Res. Phila. 2014;7(4):418-425.

12. Yang Q, Diamond MP, Al-Hendy A. Early Life Adverse Environmental Exposures Increase the Risk of Uterine Fibroid Development: Role of Epigenetic Regulation. Front. Pharmacol. 2016;7:40.

13. Cao Y, Wang Z, Gu J, Hu F, Qi Y, Yin Q, Sun Q, Li G, Quan B. Reproductive Factors but Not Hormonal Factors Associated with Thyroid Cancer Risk: A Systematic Review and MetaAnalysis. BioMed Res. Int. 2015;2015:103515.

14. Luoto R, Grenman S, Salonen S, Pukkala E. Increased risk of thyroid cancer among women with hysterectomies. Am. J. Obstet. Gynecol. 2003;188(1):45-48.

15. Rossing MA, Voigt LF, Wicklund KG, Daling JR. Reproductive Factors and Risk of Papillary Thyroid Cancer in Women. Am. J. Epidemiol. 2000;151(8):765-772.

16. Truong T, Orsi L, Dubourdieu D, Rougier Y, Hémon D, Guénel P. Role of goiter and of menstrual and reproductive factors in thyroid cancer: a population-based case-control study in New Caledonia (South Pacific), a very high incidence area. Am. J. Epidemiol. 2005;161(11):1056-1065.

17. Altman $\mathrm{D}$, Yin $\mathrm{L}$, Falconer $\mathrm{H}$. Long-term cancer risk after hysterectomy on benign indications: Population-based cohort study. Int. J. Cancer 2016;138(11):2631-2638.

18. Clavel-Chapelon F, E3N Study Group. Cohort Profile: The French E3N Cohort Study. Int. J. Epidemiol. 2015;44(3):801-809.

19. Luoto R, Auvinen A, Pukkala E, Hakama M. Hysterectomy and subsequent risk of cancer. Int. J. Epidemiol. 1997;26(3):476-483.

20. Wong EY, Ray R, Gao DL, Wernli KJ, Li W, Fitzgibbons ED, Feng Z, Thomas DB, Checkoway $\mathrm{H}$. Reproductive history, occupational exposures, and thyroid cancer risk among women textile workers in Shanghai, China. Int. Arch. Occup. Environ. Health 2006;79(3):251-258.

21. Negri E, Dal Maso L, Ron E, La Vecchia C, Mark SD, Preston-Martin S, McTiernan A, Kolonel L, Yoshimoto Y, Jin F, Wingren G, Rosaria Galanti M, Hardell L, Glattre E, Lund E, Levi F, Linos D, Braga C, Franceschi S. A pooled analysis of case-control studies of thyroid cancer. II. Menstrual and reproductive factors. Cancer Causes Control 1999;10(2):143-155.

22. Mack WJ, Preston-Martin S, Bernstein L, Qian D, Xiang M. Reproductive and hormonal risk factors for thyroid cancer in Los Angeles County females. Cancer Epidemiol. Biomark. Prev. Publ. Am. Assoc. Cancer Res. Cosponsored Am. Soc. Prev. Oncol. 1999;8(11):991-997.

23. Brinton LA, Gridley G, Persson I, Baron J, Bergqvist A. Cancer risk after a hospital discharge diagnosis of endometriosis. Am. J. Obstet. Gynecol. 1997;176(3):572-579.

24. Melin A, Sparén $P$, Bergqvist $A$. The risk of cancer and the role of parity among women with endometriosis. Hum. Reprod. Oxf. Engl. 2007;22(11):3021-3026. 
25. Brinton LA, Westhoff CL, Scoccia B, Lamb EJ, Althuis MD, Mabie JE, Moghissi KS. Causes of infertility as predictors of subsequent cancer risk. Epidemiol. Camb. Mass 2005;16(4):500-507.

26. Melin A, Sparén P, Persson I, Bergqvist A. Endometriosis and the risk of cancer with special emphasis on ovarian cancer. Hum. Reprod. Oxf. Engl. 2006;21(5):1237-1242.

27. Sweet MG, Schmidt-Dalton TA, Weiss PM, Madsen KP. Evaluation and management of abnormal uterine bleeding in premenopausal women. Am. Fam. Physician 2012;85(1):35-43.

28. Lee J-H, Kim Y, Choi J-W, Kim Y-S. The association between papillary thyroid carcinoma and histologically proven Hashimoto's thyroiditis: a meta-analysis. Eur. J. Endocrinol. 2013;168(3):343-349.

29. Pazaitou-Panayiotou K, Michalakis K, Paschke R. Thyroid cancer in patients with hyperthyroidism. Horm. Metab. Res. 2012;44(4):255-262.

30. Spinos N, Terzis G, Crysanthopoulou A, Adonakis G, Markou KB, Vervita V, Koukouras D, Tsapanos V, Decavalas G, Kourounis G, Georgopoulos NA. Increased frequency of thyroid nodules and breast fibroadenomas in women with uterine fibroids. Thyroid Off. J. Am. Thyroid Assoc. 2007;17(12):1257-1259.

31. Kim M-H, Park YR, Lim D-J, Yoon K-H, Kang M-I, Cha B-Y, Lee K-W, Son H-Y. The relationship between thyroid nodules and uterine fibroids. Endocr. J. 2010;57(7):615-621.

32. Ott J, Kurz C, Braun R, Promberger R, Seemann R, Vytiska-Binstorfer E, Walch K. Overt hypothyroidism is associated with the presence of uterine leiomyoma: a retrospective analysis. Eur. J. Obstet. Gynecol. Reprod. Biol. 2014;177:19-22.

33. Huang Y, Dong W, Li J, Zhang H, Shan Z, Teng W. Differential expression patterns and clinical significance of estrogen receptor- $\alpha$ and $\beta$ in papillary thyroid carcinoma. BMC Cancer 2014;14:383.

34. Bertoni APS, Brum IS, Hillebrand AC, Furlanetto TW. Progesterone Upregulates Gene Expression in Normal Human Thyroid Follicular Cells. Int. J. Endocrinol. 2015;2015:864852.

35. Kawabata W, Suzuki T, Moriya T, Fujimori K, Naganuma H, Inoue S, Kinouchi Y, Kameyama K, Takami H, Shimosegawa T, Sasano H. Estrogen receptors (alpha and beta) and 17betahydroxysteroid dehydrogenase type 1 and 2 in thyroid disorders: possible in situ estrogen synthesis and actions. Mod. Pathol. Off. J. U. S. Can. Acad. Pathol. Inc 2003;16(5):437-444.

36. Borahay MA, Al-Hendy A, Kilic GS, Boehning D. Signaling Pathways in Leiomyoma: Understanding Pathobiology and Implications for Therapy. Mol. Med. Camb. Mass 2015;21:242-256.

37. Zane M, Catalano V, Scavo E, Bonanno M, Pelizzo MR, Todaro M, Stassi G. Estrogens and stem cells in thyroid cancer. Front. Endocrinol. 2014;5:124.

38. Hulchiy M, Zhang H, Cline JM, Hirschberg AL, Sahlin L. Receptors for thyrotropin-releasing hormone, thyroid-stimulating hormone, and thyroid hormones in the macaque uterus: effects of long-term sex hormone treatment. Menopause 2012;19(11):1253-1259.

39. Fröhlich E, Wahl R. Mechanisms in Endocrinology: Impact of isolated TSH levels in and out of normal range on different tissues. Eur. J. Endocrinol. 2016;174(2):R29-41.

40. Douple EB, Mabuchi K, Cullings HM, Preston DL, Kodama K, Shimizu Y, Fujiwara S, Shore RE. Long-term radiation-related health effects in a unique human population: lessons learned from the atomic bomb survivors of Hiroshima and Nagasaki. Disaster Med. Public Health Prep. 2011;5 Suppl 1:S122-133. 
41. Malaguarnera R, Vella V, Nicolosi ML, Belfiore A. Insulin Resistance: Any Role in the Changing Epidemiology of Thyroid Cancer? Front Endocrinol (Lausanne). 2017;8:314.

Table 1: Patients characteristics according to baseline hysterectomy status. E3N cohort, 1990-2011 $(n=89,340)$

Ever

History of dysthyroidism

Never

Ever

History of goiter or thyroid nodules

Never

Ever

Body mass index, $\left(\mathrm{kg} / \mathrm{m}^{2}\right)$

$<18.5$

[18.5-22.5[

$\geq 30$

Age at menarche (years)

$<13$

$\geq 13$

Use of oral contraceptives

Never

\section{No hysterectomy $(n=80,197)$}

(\%)

$\pm 6.5$

48.8

43,121

37,076
3479

43,894

19,659

10,932

2233

74,838

5359

79,588

609

(54.7)

43,443

33,644

(42.0)

36,754
5451

3692

ysterectomy $(n=9143)$

n $\quad(\%)$

3.1

6.2

$(46,2)$

8292

851

851

9056

87

(1.0)

4463

4680

436

1870

6000

(65.6) 
Infertility treatment

Never

Ever

\section{Parity and age at first full-term pregnancy}

Nulliparous

One child at age $<30$

One child at age $\geq 30$

2 or more children, the first at age $<30$

2 or more children, the first at age $\geq 30$

\section{Menopausal status and use of MHT at baseline}

Premenopausal

Postmenopausal with no recent use of MHT

Postmenopausal with recent use of MHT

Postmenopausal with unknown use of MHT

Menopausal status at the end of the follow-up

Premenopausal

Postmenopausal

Age at menopausal at the end of follow-up

Mean \pm standard deviation
8987

8956

51,692

16,273

4828

(6.0)

148

(1.6)

8499

644

3848

(4.8)

(66.4)

(6.4)

1278

7446

3749

4786

(6.0)

75,369

(94.0)

8995

(98.4) 
Table 2: Hazard ratios (HRs) and $95 \%$ confidence intervals $(95 \% \mathrm{Cl})$ for differentiated thyroid cancer according to medical history of hysterectomy. E3N cohort, 1990-2011 ( $n=89,340)$

\begin{tabular}{|c|c|c|c|c|c|}
\hline & & & M1 & M2 & M3 \\
\hline & $\begin{array}{l}\text { Non-cases } \\
(\mathrm{N}=88928)\end{array}$ & $\begin{array}{l}\text { Cases } \\
(\mathrm{N}=412)\end{array}$ & HR (95\% Cl) & HR (95\% Cl) & HR (95\% Cl) \\
\hline \multicolumn{6}{|l|}{ Hysterectomy } \\
\hline Never & 72,864 & 295 & ref & ref & ref \\
\hline Ever & 16,064 & 117 & $2.22(1.79 ; 2.76)$ & $2.05(1.65 ; 2.55)$ & $2.15(1.72 ; 2.69)$ \\
\hline \multicolumn{6}{|l|}{ Surgical intervention } \\
\hline No intervention & 69,278 & 283 & ref & ref & ref \\
\hline HT and oophorectomy & 8853 & 65 & $2.40(1.82 ; 3.16)$ & $2.21(1.67 ; 2.91)$ & $2.35(1.77 ; 3.11)$ \\
\hline Oophorectomy alone & 3586 & 12 & $1.04(0.58 ; 1.85)$ & $0.98(0.55 ; 1.75)$ & $1.00(0.56 ; 1.79)$ \\
\hline HT alone & 7211 & 52 & $2.05(1.52 ; 2.76)$ & $1.89(1.41 ; 2.55)$ & $1.96(1.46 ; 2.65)$ \\
\hline \multicolumn{6}{|l|}{ Age at HT (years old) } \\
\hline No HT & 72,864 & 295 & ref & ref & ref \\
\hline$\leq 40$ & 2386 & 25 & $2.79(1.85 ; 4.20)$ & $2.55(1.70 ; 3.85)$ & $2.69(1.78 ; 4.08)$ \\
\hline ]40-45] & 3550 & 27 & $2.01(1.35 ; 2.98)$ & $1.88(1.27 ; 2.79)$ & $1.97(1.32 ; 2.93)$ \\
\hline$>45$ & 10,128 & 65 & $2.15(1.64 ; 2.82)$ & $1.98(1.50 ; 2.60)$ & $2.08(1.57 ; 2.74)$ \\
\hline$P$-trend & & & 0.69 & 0.73 & 0.89 \\
\hline \multicolumn{6}{|l|}{ Time since HT (years) } \\
\hline No HT & 72,864 & 295 & ref & ref & ref \\
\hline$\leq 5$ & 846 & 21 & $2.12(1.36 ; 3.32)$ & $2.01(1.29 ; 3.14)$ & $2.14(1.37 ; 3.35)$ \\
\hline ]5-10] & 1588 & 28 & $2.41(1.63 ; 3.56)$ & $2.23(1.51 ; 3.29)$ & $2.37(1.60 ; 3.51)$ \\
\hline ]10-15] & 2458 & 19 & $1.70(1.07 ; 2.72)$ & $1.55(0.97 ; 2.48)$ & $1.63(1.02 ; 2.61)$ \\
\hline$>15$ & 11,172 & 49 & $2.47(1.79 ; 3.40)$ & $2.27(1.64 ; 3.12)$ & $2.33(1.69 ; 3.22)$ \\
\hline P-trend & & & 0.54 & 0.60 & 0.74 \\
\hline
\end{tabular}

BMI: body mass index; HT: hysterectomy; MHT: menopausal hormone therapy

M1: Model adjusted for age (time-scale), and stratified by 5-year category birth cohort (to consider a potential age-cohort effect)

M2: M1 further adjusted for smoking status (ever/never, time-dependent), history of dysthyroidism (hyperthyroidism or hypothyroidism) (ever/never, time-dependent), history of other benign thyroid disease (nodule or goiter) (ever/never, time-dependent) and BMI $(<18.5 /[18.5-22.5[/[22.5-25[/[25-30[/ \geq 30$, time-dependent)

M3: M2 further adjusted for age at menarche (<13 years/ $\geq 13$ years), use of oral contraceptives (ever/never, time-dependent), infertility treatment (ever/never, last assessed in 1992), parity and age at first full-term pregnancy (nulliparous/one child at age $<30$ /one child at age $\geq 30 /$ two children or more, the first at age $<30$ /two children or more, the first at age $\geq 30$ ), age at menopause and use of MHT (premenopausal/postmenopausal with no recent use of MHT/postmenopausal with recent use of MHT/postmenopausal with use of MHT but unknown recency, time-dependent). 
Table 3: Hazard ratios (HRs) and $95 \%$ confidence intervals $(95 \% \mathrm{Cl})$ for differentiated thyroid cancer according to benign gynecological diseases. E3N cohort, 1990-2011 ( $n=89,340)$

\begin{tabular}{|c|c|c|c|c|c|}
\hline & & & M1 & M2 & M3 \\
\hline & $\begin{array}{l}\text { Non-cases } \\
(\mathrm{N}=88928)\end{array}$ & $\begin{array}{l}\text { Cases } \\
(\mathrm{N}=412)\end{array}$ & $\mathrm{HR}(95 \% \mathrm{Cl})$ & $\mathrm{HR}(95 \% \mathrm{Cl})$ & $\mathrm{HR}(95 \% \mathrm{Cl})$ \\
\hline History of benign gyne & & & & & \\
\hline Never & 41,845 & 166 & ref & ref & ref \\
\hline Self-reported & 47,083 & 246 & $1.71(1.40 ; 2.09)$ & $1.58(1.29 ; 1.93)$ & $1.59(1.30 ; 1.95)$ \\
\hline Medically confirmed & 36,793 & 191 & $1.82[1.47 ; 2.25]$ & $1.63[1.31 ; 2.03]$ & $1.63[1.31 ; 2.02]$ \\
\hline Surgically confirmed & 27,465 & 143 & $1.87[1.48 ; 2.35]$ & $1.67[1.32 ; 2.11]$ & $1.66[1.31 ; 2.10]$ \\
\hline Fibroid history & & & & & \\
\hline Never & 60,986 & 244 & ref & ref & ref \\
\hline Self-reported & 27,942 & 168 & $1.87(1.53 ; 2.28)$ & $1.71(1.40 ; 2.08)$ & $1.73(1.41 ; 2.11)$ \\
\hline Medically confirmed & 21,198 & 127 & $1.95(1.57 ; 2.43)$ & $1.74(1.40 ; 2.17)$ & $1.75(1.40 ; 2.19)$ \\
\hline Surgically confirmed & 14,725 & 94 & $2.16(1.69 ; 2.76)$ & $1.91(1.50 ; 2.44)$ & $1.93(1.51 ; 2.48)$ \\
\hline Endometriosis history & & & & & \\
\hline Never & 82,322 & 376 & ref & ref & ref \\
\hline Self-reported & 6606 & 36 & $1.39(0.99 ; 1.96)$ & $1.26(0.90 ; 1.78)$ & $1.27(0.90 ; 1.79)$ \\
\hline Medically confirmed & 5096 & 27 & $1.39(0.94 ; 2.06)$ & $1.25(0.85 ; 1.86)$ & $1.26(0.85 ; 1.86)$ \\
\hline Surgically confirmed & 3922 & 20 & $1.32(0.84 ; 2.07)$ & $1.20(0.76 ; 1.88)$ & $1.19(0.76 ; 1.88)$ \\
\hline Uterine polyp history & & & & & \\
\hline Never & 70,291 & 329 & ref & ref & ref \\
\hline Self-reported & 18,637 & 83 & $1.22(0.96 ; 1.55)$ & $1.15(0.90 ; 1.46)$ & $1.15(0.90 ; 1.47)$ \\
\hline Medically confirmed & 13,700 & 57 & $1.19(0.89 ; 1.58)$ & $1.09(0.82 ; 1.45)$ & $1.09(0.82 ; 1.45)$ \\
\hline Surgically confirmed & 11,436 & 49 & $1.21(0.89 ; 1.64)$ & $1.11(0.82 ; 1.51)$ & $1.11(0.82 ; 1.50)$ \\
\hline Ovarian cyst history & & & & & \\
\hline Never & 73,665 & 336 & ref & ref & ref \\
\hline Self-reported & 15,263 & 76 & $1.32(1.03 ; 1.69)$ & $1.23(0.96 ; 1.58)$ & $1.24(0.96 ; 1.59)$ \\
\hline Medically confirmed & 11,121 & 58 & $1.44(1.09 ; 1.91)$ & $1.31(0.99 ; 1.74)$ & $1.32(0.99 ; 1.75)$ \\
\hline Surgically confirmed & 8211 & 41 & $1.42(1.03 ; 1.97)$ & $1.29(0.93 ; 1.78)$ & $1.30(0.94 ; 1.81)$ \\
\hline
\end{tabular}

BMl: body mass index; HT: hysterectomy; MHT: menopausal hormone therapy

M1: Model adjusted for age (time-scale), and stratified by 5-year category birth cohort (to consider a potential age-cohort effect)

M2: M1 further adjusted for smoking status (ever/never, time-dependent), history of dysthyroidism (hyperthyroidism or hypothyroidism) (ever/never, time-dependent), history of other benign thyroid disease (nodule or goiter) (ever/never, time-dependent) and BMl (<18.5/[18.5-22.5[/[22.5-25[/[25-30[/ $\geq 30$, time-dependent)

M3: M2 further adjusted for age at menarche (<13 years/ $\geq 13$ years), use of oral contraceptives (ever/never, time-dependent), infertility treatment (ever/never, last assessed in 1992), parity and age at first full-term pregnancy (nulliparous/one child at age <30/one child at age $\geq 30 /$ two children or more, the first at age $<30 /$ two children or more, the first at age $\geq 30$ ), age at menopause and use of MHT (premenopausal/postmenopausal with no recent use of $\mathrm{MHT} /$ postmenopausal with recent use of MHT/postmenopausal with use of MHT but unknown recency, time-dependent). 
Risk of thyroid cancer according to the mode of diagnosis of fibroids and the absence of a history of hysterectomy

Hazard ratio and $95 \% \mathrm{Cl}$ are displayed from the multivariate model 2

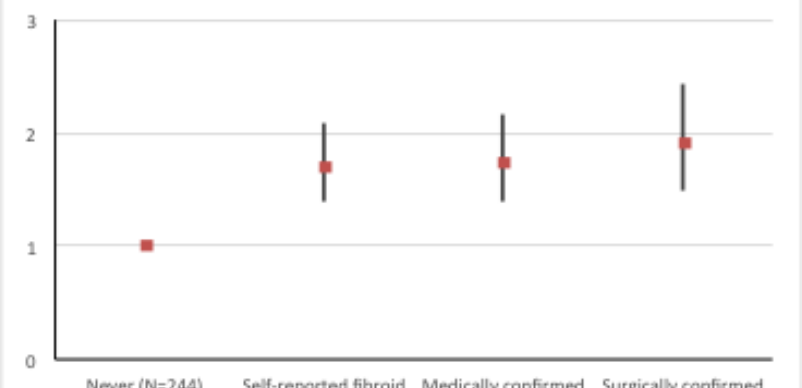

Never ( $N=244)$ Self-reported fibroid. Medically confirmed Surgically confirmed history ( $N=168) \quad$ fibroid history fibroid history ( $N=94)$ $(\mathrm{N}=127)$ 